\title{
Theoretical Annotation of China's National Audit System Change
}

\author{
Kangli Liao, Feng Wang* \\ Accounting College, Jiujiang University, Jiujiang City, China \\ Email address: \\ liaokangli@126.com (Kangli Liao), 931435666@qq.com (Feng Wang) \\ ${ }^{*}$ Corresponding author
}

To cite this article:

Kangli Liao, Feng Wang. Theoretical Annotation of China's National Audit System Change. Journal of Finance and Accounting. Vol. 7, No. 4, 2019, pp. 107-115. doi: 10.11648/j.jfa.20190704.11

Received: July 4, 2019; Accepted: July 26, 2019; Published: August 13, 2019

\begin{abstract}
Economic interests (economic rationality) and political interests (political rationality) are the dual goals pursued by political state in promoting structural reform. Improving the independence of the national audit as the premise in the national audit system reform, simultaneously not challenging the existing political system, in this paper we construct Pareto Optimality Model with "independence" and "political control ability" as the basic variables and "political state-economic society" as the basic stakeholders with dichotomy, draw Pareto Optimality interval of "political control ability" under the condition of considering transaction costs. Based on stakeholders formed by the national audit system reform in the past 30 years, we further decompose and integrate the stakeholders with dichotomy, and construct a dynamic model of the national audit system reform with the central government, local interest groups and the public as stakeholders, thus to explain theoretically the reform course of national audit system. As fundamental reform in the national audit system that exceeds the constraints of political system and historical tradition is unlikely to occur in a short time, in this paper we put forward promoting the internal optimization of national audit system under the existing political system framework to realize the interaction between good governance of the state and good performance of the national audit.
\end{abstract}

Keywords: National Audit, National Audit System, Pareto Optimality, National Governance, Institutional Change

\section{Introduction}

The basic pattern of China's national audit system has been in use since it was established in the early 1980s. The reform of the national audit system has been concerned on theory for many years, but it has been neglected in practice. This apparent contrast seems to confirm Douglas North's earlier research conclusion that efficiency-oriented institutional changes often fail to occur due to political constraints [1-2].

In his study of economic history, North had put forward a paradoxical conclusion about the state that "the existence of the state is the key to economic growth, but the state is the source of economic recession" [3]. On the one hand, the state promotes economic growth for the purpose of increasing tax revenue, on the other hand, it maximizes the power rent by identifying the basic rules of competition and cooperation that form the property right structure, i.e., the state has dual objectives of "economic benefit (economic rationality)" and "political benefit (political rationality)". In fact, these two goals are often difficult to coincide with each other, thus forming a national paradox. The key to understand "political rationality" in North's state paradox is the identification of "power rent". From the perspectives of finance, rent must occur in a certain time series, which can be decomposed into "single-term rent (annuity)", "duration" and "time preference (discount rate)". Under the hypothesis of low time preference, "duration" has become the key to achieve the goal of "rent maximization" in political state, i.e., only under the premise of political stability, political state will consider how to increase the single-term rent.

This provides a new perspective for understanding China's national audit system reform. In order to implement the reform (optimization) of the national audit system, two basic conditions must be met simultaneously: First, the reform of the audit system must be premised on improving the independence of the national audit; Second, the reform of the audit system cannot challenge the existing political system (or surpass political reform). The former is the objective of audit 
system reform, which can be regarded as the requirement of economic rationality, while the latter is the feasibility requirement of audit system reform, which can be regarded as the requirement of political rationality. In fact, the above appreciation can be deduced in theory and verified in practice. In theory, assuming that the initial audit system is A, as long as the political state proves experientially that: (1) system B $(\mathrm{B} \neq \mathrm{A})$ is superior in economy (economic rationality) and not inferior in politics (political rationality), (2) orsuperior in politics (political rationality) and not inferior in economy (economic rationality), then the political state will abandon $\mathrm{A}$ for $\mathrm{B}$ or at least have motivation to abandon $\mathrm{A}$ for $\mathrm{B}$. This criterion of "better than and not inferior" is the basis of Pareto Optimality. In practice, the experience of China's reform shows that any institutional reform can't go against national interests, which constitutes a bottom line in institutional reform [4]. Comrade Deng Xiaoping stressed that "In China today, we should never extol the spontaneity of the masses without the leadership of the Party" [5]. Only when the experience from the bottom is proved to meet the constitutional requirements, can it be accepted and legalized. Later the criteria of "three benefits" has been formed to evaluate the success or failure of the reform. Among the criteria of "three benefits", developing the productive forces is the prerequisite, i.e., any reform which is promoted must be conducive to the development of the productive forces rather than restricting the development of the productive forces. On this premise, it is necessary to meet the requirements of "enhancing the comprehensive national power" and "improving the living standards of the people", i.e., realizing the dual promotion of "the country's wealth" and "the people's health", i.e., realizing the synchronous propulsion of politics and economy.

Based on above comprehension this paper will analyze and discuss the change, reform and optimization of China's national audit system from the dual perspectives of institutional change theory and China's reality. Although there are many ways for the national system reform, there are two most important ways: one is the position of audit institutions in the national power structure, the other is the relationship between superior and inferior audit institutions. Under the current bureaucratic administrative system, it is not suitable to analyze the relationship between superior audit authorities and inferior audit authorities with the perspective of "economic interest (economic rationality)" and "political interest (political rationality)". Therefore, the national audit system reform discussed in this paper is mainly identified that "audit institutions are under the national power structure". In this paper, firstly it establishes a general Pareto Optimality Model for the reform (optimization) of the national audit system, and describes the Pareto Optimality interval based on "political control ability" (political rationality) considering transaction costs. Secondly, it decomposes and integrates the variables in the ideal "utopian" Pareto Optimality Model, according to the actual course of China's economic and social development. Finally, on the basis of inferring whether the fundamental changes of the national audit system can take place in the near future or not, along the way of theoretical development of the national audit, this paper explores the optimization direction of the interaction between the "good governance" of national governance and the "good effect" of national audit in the process of national governance.

The academic contributions or innovations of this paper are mainly embodied in the following aspects: Firstly, the basic principles of Pareto Optimality are used to analyze the mechanism of the optimization of national audit system. Secondly, a new deconstruction of the "interests" and "stakeholders" involved in the optimization of national audit system is made, which serves as the theoretical basis for interpreting the changes of national audit system in China. Thirdly, the optimization direction of interaction between national governance and national audit is put forward.

\section{The Analysis of Pareto Optimality for the National Audit System Change}

\subsection{The Implication of Pareto Optimality for the National Audit System Change}

In this paper, Pareto Optimality is used to define the optimization of national audit system. If the change of national audit system enhances interests of one party (or more parties) of stakeholders, meanwhile, it does not damage the interests of any party, in this case, the change of the national audit system will be effective and progressive. If the progress of national audit system change is defined by Pareto Optimality, the change cannot damage interests of any parties after reform. The following problem is the identification of "stakeholders" and "interests".

Theoretically, national audit is an important part of the national system [6], the change of the national audit system involves everyone's interest, so everyone is the "stakeholder" of national audit system change. A "unanimous agreement" principle could solve this public problem, argued by Stevens (1999), Buchanan and Toulok (2000) [7]. The national audit system includes the status of the state audit institution in the national governance system and the relationship between the state audit institutions. [8]. According to the realities of China today, "political state" is a vital stakeholder in the institutional change. At present the core of the national audit system is to coordinate the relationship between political state and economic society. Therefore, in this paper "political state" and "economic society" are regarded as the basic stakeholders in the national audit system change with dichotomy.

In this paper we appraise the "interests" of the national audit institutional change from two aspects of "economic interests (economic rationality)" and "political interests (political rationality)", thus the requirement of Pareto Optimality for the national audit system change is defined, i.e., in order to implement the reform (optimization) of the national audit system, two compulsory conditions must be met simultaneously: First, the audit system reform (Optimality) must be premised on improving the independence of national audit. Second, the reform of audit system can't challenge the 
existing political system (without weakening the power rent of political state). The former is the objective of audit system reform, which can be regarded as the requirement of economic rationality, while the latter is the feasibility requirement of audit system reform, which can be regarded as the requirement of political rationality.

\subsection{Further Analysis of Political Interests (Political Rationality)}

In North's paradox of state, "economic interest (economic rationality)" and "political interest (political rationality)" have become the dual objectives of a political state, while its political interest mainly achieves the maximization of power rent by identifying the basic rules of competition and cooperation which form the property structure. In the view of finance, rental income should be placed on a specific time series in any case, i.e., rental income occurring at any time point can be positioned at another time point through discount (present value or final value), so that rental income at different time points could be comparable. Therefore, rent could be divided into three aspects: single-term rent, duration of rent and time preference. Discount rate is often used to measure "time preference" in economics. Samuelson (1937) put forward the important hypothesis that "people's time preference is dynamically consistent", i.e., constant discount rate hypothesis, when he constructed the discount utility model. This means that when people compare the benefits of time series, their relative time preferences are stable and will not change when the interests in time series are advanced or delayed for the same time. Samuelson's hypothesis provides ideas for this paper to analyze power rent appraised by political countries: Its time preference (discount rate) is dynamically consistent (be constant) for any interest subject, so interests mainly depends on the amount of interests at each time point and the ultimate duration of interests. In other word, when the single-term rent income can be obtained steadily (such as annuity), in order to maximize the power rent, the political state only needs to pursue the maximization of the duration of rent. Therefore, when political state faces any decision of institution reform, political stability is always the most essential constraint, and political stability represents the political control ability of the political state which is the political state's discretional ability of resources.

\subsection{The Model of Pareto Optimality for National Audit System Reform (Optimization)}

In this paper, the independence of the national audit system is defined as $Q$. The independence before and after the audit system reform is $Q_{1}$ and $Q_{2}$ respectively. Improving the independence of the national audit system is the basic requirement for the national audit system reform and the basic condition to determine the quality of the national audit. Therefore, the reform must meet $Q_{2}>Q_{1}$. The political control capability coefficient of political state is $R$, the political control capability coefficient before and after the change of the audit system is $R_{1}$ and $R_{2}$ respectively. Broadly speaking, the reform of the national audit system is the reform of the government. As long as the independence of audit is strengthened, it will affect the interests of the government and some officials in the short term. Therefore, $R_{2}<R_{1}$. Because the independence and political control ability before and after the national audit system reform is asymmetric $\left(Q_{2}>\right.$ $Q_{1}$ and $R_{2}<R_{1}$ ), it is possible to achieve theoretically Pareto Optimality of the national audit system reform. As mentioned previously, $\mathrm{R}$ represents the coefficient of political control, then (1-R) represents weakening the ability of political control and the government's discretion to resources. Therefore, when $Q_{2} R_{2}>Q_{1} R_{1}$ and $R_{2}>Q_{1} R_{1} /_{Q_{2}}$, the national audit system reform preferentially meets the requirements of improving independence. When $Q_{2}\left(1-R_{2}\right)>Q_{1}\left(1-R_{1}\right)$, i.e., $R_{2}<1-Q_{1}\left(1-R_{1}\right) /_{Q_{2}}$, the national audit system reform have the priority to meet the requirements of maintaining the political control ability for the political state. According to the definition of Pareto Optimality mentioned above, it could be concluded that the basic constraints for the realization of Pareto Optimality in the national audit system reform is $Q_{1} R_{1} / Q_{2}<R_{2}<1-Q_{1}\left(1-R_{1}\right) /_{Q_{2}}$ which is the requirement for the coefficient of political control ability after system reform. When this requirement is met, the national audit system reform will achieve a win-win situation of economic rationality and political rationality, and the system reform which achieves Pareto Optimality will be stably sustainable.

In the view of decision-making on system reform by political state, it is necessary to compare the basic cost and benefit, i.e., whether the cost spent in the process of system reform in order to achieve the fixed goal and the loss of stakeholders caused by changes can be compensated through the potential benefit of system reform or not. If the compensation can be realized, and the net present value of income can finally be positive, then the national audit system reform meets the conditions of Pareto Optimality, which could be expressed in the following form in view of accounting present value:

$$
V=-\mathrm{C}+\sum_{\mathrm{t}}^{\mathrm{T}} \frac{\mathrm{P}_{0}+\mathrm{P}_{\mathrm{M}}}{(1+\mathrm{i})^{\mathrm{t}}}
$$

Among them: $\mathrm{V}$ is the net income of the national audit system reform; $\mathrm{C}$ is the governance cost of the government promoting the audit system reform; $\mathrm{P}_{0}$ is the net income (or net loss) brought by the improvement of the independence after the national audit system reform; $\mathrm{P}_{\mathrm{M}}$ is the potential net income (or net loss) of the power rent of the political state after the system reform. I represent the time preference (discount rate), whose constant hypothesis has been demonstrated previously. $\mathrm{T}$ is the time flow within the expected time range when audit system reform is to be effective.

From political states' perspectives, if the reform of audit system meets Pareto Optimality, at least $\mathrm{V}>0$, i.e., $\sum_{\mathrm{t}}^{\mathrm{T}} \frac{\mathrm{P}_{0}+\mathrm{P}_{\mathrm{M}}}{(1+\mathrm{i})^{\mathrm{t}}}>\mathrm{C}$.

As mentioned previously, assuming that $\mathrm{R}$ represents the 
coefficient of political control ability, the larger $\mathrm{R}$ represents the stronger political control ability. As long as the government has enough willingness to promote the system reform, it will come up against less resistance (In fact, the biggest resistance of the system reform comes from the government itself), the cost of governance (C) will be correspondingly less, i.e., there is a reverse relationship between the cost of governance (C) and political control capability coefficient (R), as shown in Figure 1. Region II is the Pareto Optimality interval of the national audit system. In this region, the cost of governance $(\mathrm{C})$ is reasonable and controllable, meanwhile, the coefficient of political control ability remains within the range of Pareto Optimality.

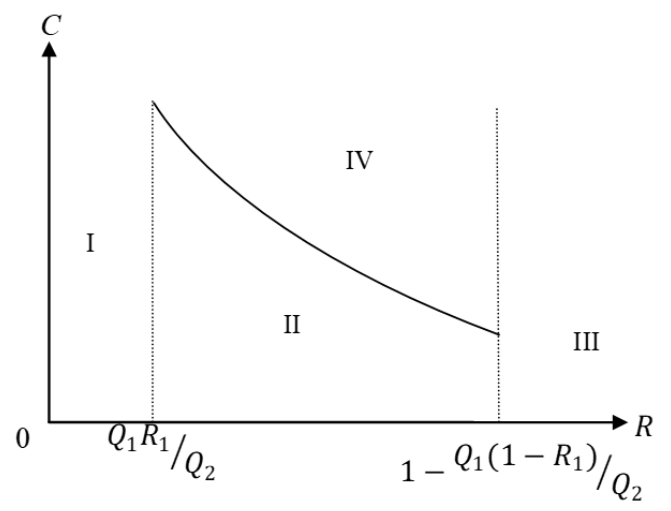

Figure 1. Pareto Optimality Interval of the National Audit System Reform.

When the "political control capability coefficient" $R_{2}$ after the audit system reform is in the interval [ $Q_{1} R_{1} / Q_{2}, 1-$ $\left.Q_{1}\left(1-R_{1}\right) /_{Q_{2}}\right]$ and the government cost is reasonably controllable (regional II), Pareto Optimality of the audit system reform can be realized. Only when $R_{2}$ is in the interval $\left[Q_{1} R_{1} / Q_{2}, 1-Q_{1}\left(1-R_{1}\right) / Q_{2}\right]$, the cost of governance exceeds the controllable range, and Pareto Optimality of audit system reform is not necessarily possible (regional IV); When $R_{2}<Q_{1} R_{1} / Q_{2}$ (regional I), the audit system reform has been completely controlled by the political state, the independence of the national audit has been further weakened, and the reformed audit system may exist in name only. When $R_{2}>1-Q_{1}\left(1-R_{1}\right) / Q_{2}$ (Regional III), it means that the independence of national auditing has been greatly improved, however, because this kind of change needs to greatly reduce the discretion of the government and officials on resources which beyond its tolerance, it is impossible to obtain support in reality.

\section{Annotation for the Change Course of China's National Audit System}

\subsection{Further Decomposition and Integration of Stakeholders with Dichotomy}

In previous part of the paper, the dichotomy of "political state-economic society" is used to divide stakeholders when constructing conditions of Pareto Optimality for national audit system reform. However, in the process of actual institutional change, the complexity of institutional reform often makes Pareto Optimality an ideal "utopia" state. Real Pareto Optimality is often difficult to achieve in reality. The dichotomy of "political state-economic society" and the decomposition of interests into "economic interests (economic rationality)" and "political interests (political interests)" are constructed as the variables which are ingenious and appropriate, but it seems too simple to analyze and evaluate the specific process of the national audit system reform. Therefore, it is necessary to further decompose and integrate the stakeholders with the dichotomy. This kind of decomposition and integration is based on stakeholders formed under the background of the political, economic and social development of our country for more than 30 years. In North's general view, the main body of institutional change can be divided into government, group and individual [9]. Huai Li and Wei Deng (2013) analyzed the relationship between the central government and local government [10]. Along this idea, this paper further decomposes the stakeholders into central government, local government, groups and individuals, then further integrates them according to their motives and mutual relations.

Central governments and local governments. The central government and local government belong to two levels of the government. In the process of institutional change, the central government, as the leader of institutional change, maintains the consistency with the interests of masses of people which are determined by the legitimacy of the government. In the specific implementation process, the local government is often difficult to avoid deviation from the central government in interests. Under the current national audit system in China, the administrative audit system makes the local government the main object of audit supervision. Therefore, the central government and local government should be different stakeholders in the national audit system reform.

Central government and groups. At present, the development of interest groups is still in its infancy, and the influence of interest groups can't affect or shake the position of the central government. Therefore, the central government and groups are different stakeholders.

Central Government and Individuals. The overall interests of the central government and masses of people are consistent. In practice, macro-overall interests are not entirely chime with micro-individual interests. Meanwhile, the long-term macro-benefits based on the perspective of the central government and the short-term benefits based on the perspective of the individual will be quite different at a certain time point, which implies the inconsistency between the central government and the individual in the pursuit of interests. Therefore, the central government and individuals are different stakeholders.

Local governments and groups. Superficially local governments and groups are different, the former belongs to the government, the latter belongs to interest groups 
composed of common interest seekers. In today's China, the relationship between local governments and groups is complex. Under fiscal decentralization, although local governments are required to keep consistent with the central government in policy direction, they have discretion of resources they control, which makes it possible for interest groups to realize specific interests through local governments. On the whole, interest groups in China can't have substantial impact on the government's decision-making. Meanwhile, the development of China's interest groups is uneven, and there is no checks and balances between interest groups. This provides space for local governments to use their "political control ability" to seek power rent, and also facilitates interest groups to influence, interfere with or participate in the local government's decision-making and the process of policy implementation in order to safeguard their own interests. Sometimes, it may form a common interest groups seeking interests of local power and groups, thus forming a "the community of local interest".

Local Government and Individuals. In general, local governments should safeguard the interests of residents within their jurisdiction. Individuals can hardly influence the decision-making of local governments (often with "motivation" but without "influence"), which causes local governments unwilling to put personal interests first in power composition, function design and policy implementation. The reform of national audit system involves the reform of government functions, powers and responsibilities. No matter which function of national audit will focus on enhancing, the interests of local governments and specific officials will be affected to different degrees in the short term. The implementation of more standardized and transparent financial behavior by local governments meets the expectations of the public, but to some extent, it will affect local governments' discretion of resources. Therefore, local government and individuals are different.

Groups and individuals. In the public (taxpayers)'s view, interests between individuals and groups are consistent, they have strong will to reform the national audit system and enhance the independence of the national audit. As long as national audit system satisfies the conditions of $R_{2}>$ $Q_{1} R_{1} /_{Q_{2}}$, the expected benefits of the public will be greater than the costs brought by institutional change. The new auditing system is superior to the old one in curbing corruption, improving performance, promoting transparency, thus provide the public with higher quality of public services. However, there are great differences between groups and individuals. On the one hand, the influence to government behavior is not equivalent, the influence of groups is obviously stronger than that of individuals. On the other hand, groups themselves have specific interests, and from the perspective of the public their attitudes toward institutional change are not necessarily hoping that the national audit system will become more independent. Therefore, groups and individuals are different stakeholders.

From what have been analyzed previously, in this paper we could further integrate the stakeholders in the national audit system reform. As the leading party of the system reform, the central government keeps neutral with individuals, groups and local governments in the pursuit of interests, so it can be regarded as a party of the stakeholders. The public which is composed of individuals and groups is in audience position because of their lack of influence in policy making, but their interests are "the interests of the overwhelming majority of the people", which are the starting point of the national audit system reform, so it could be regarded as a party of the stakeholders. Local governments have dual nature in pursuit of interests: on the one hand, they should keep consistent with the central government in the direction of policies; on the other hand, they are influenced by interest groups in implementation of policies, forming a common interest body named the community of local interest including local government and group interests, so it becomes a party of the stakeholders. The decomposition and combination of stakeholders mentioned above are shown in Figure 2.

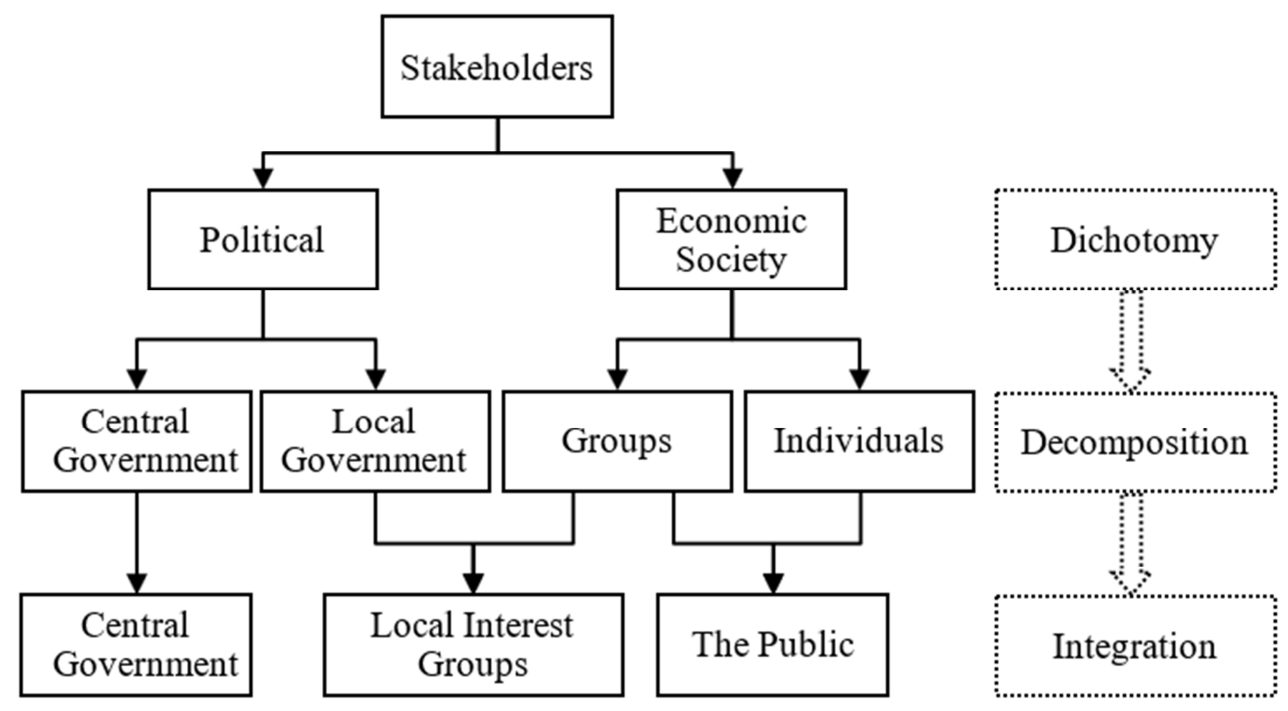

Figure 2. Decomposition and Integration of the Stakeholders. 


\subsection{Dynamic Model of National Audit System Reform}

Junwei Lu and Hong Yin (2012) set up a general dynamic model of the government accounting reform [11]. We refer to their track of analysis in this paper to build up a dynamic model of national audit system reform. In the change of national audit system, different stakeholders will support (promote) or oppose (hinder) the system reform to some degree based on the expected cost-benefit. Assuming that the system reform is carried out, the New National Audit System (NAS) will be the result of one or more "reform strategies" (RS) imposed on the Old National Audit System (OAS), i.e., the new National Audit System (NAS) is the function of the Old National Audit System (OAS) and Reform Strategies (RS).

$$
N A S=f(O A S, R S)
$$

Define the ultimate impact of each stakeholder on the national audit system reform as the "force" of $F$ which is mainly constrained by both "motivation" and "influence" of stakeholders. The "motivation" of stakeholders depends mainly on the trade-off between expected cost and benefit. i.e. the choice of "reform strategy" (RS), while "influence" is mainly affected by the existing factors of "institutional environment" (IE). Therefore, the "force" (F) could be regarded as a function of "reform strategy" (RS) and "institutional environment" (IE).

$$
F=f(R S, I E)
$$

We could deduce that the motive force of the national audit system reform is the balanced result of the "forces" of all stakeholders. The general model is

$$
G A R P=f\left[f_{c g}(R S, I E), f_{l i}(R S, I E), f_{s p}(R S, I E)\right]
$$

Among them, $f_{c g}(R S, I E)$ is the function of the central government, $f_{l i}(R S, I E)$ is the function of local interest groups, $f_{s p}(R S, I E)$ is the function of the public forces.

\subsection{Annotation for the Change of the National Audit System}

Although central government is the leader of the national audit system reform which is mandatory, local interest groups will have the motivation and ability to influence and change the progress and results of institutional reform when the results of institutional change conflict with the interests of local interest groups: on the one hand, the local interest groups as the executor of policy could adjust the policies or implement selectively policies according to their own interests; on the other hand, the local interest groups could be used as a bridge between the central government and the public and block the information interaction between them. The feedback mechanism in a bottom-up way can mislead or exert pressure on the central government, so that they ultimately influence policy from the central government. Fiscal decentralization enables local governments to have more flexible financial and administrative powers. If the national audit system reform advances along the way of Pareto Optimality, it will put the power of local governments under the supervision of audit, its "ability of political control" will inevitably be constrained, thus local governments will hinder the progress of the national audit system reform in the action of "political rationality". In a certain sense, local interest groups play important role in mandatory institutional change, even in certain circumstances, local interest groups play a decisive role in implementation of institutional change. In the process of induced institutional change, local interest groups and the public are the leader of institutional change, the public is difficult to form union interest demands and don't have the influence and discourse power to change the progress of the institution reform, so that local interest groups become the actual leaders of the institutional reform.

Taking a wide view of the progress of national audit reform for more than 30 years, the academic circles have reached agreement on the drawbacks of the existing system. It is very difficult to realize the real audit institutional reform on the basis of enhancing the independence of national audit. The root lies in local interest groups as the vested interest and actual controller of the institutional reform. On the one hand, the local interest groups determine concrete implement progress and results, and have the ability to implement policy selectively. On the other hand, the local interest groups have the bottom-up routes to influence the institutional reform. Local interest groups have strong motivation and ability to influence institutional change. Although the central government is the leader of institutional change, leading positions are not guaranteed. The up "policy" and the bottom "countermeasures" are unequal. Policymakers and executors are not entirely unified in their interests. In fact, the dominant position of the central government is likely to be overridden in the process of institutional change, and the interests of the public can't be effectively guaranteed. As a result, the central government often becomes a "buyer" of the negative impact of institutional change. The top-down mandatory institutional change is difficult to be implemented effectively, and the bottom-up induced institutional change is even more difficult to be promoted, which is the crux that the fundamental institutional change has not achieved in our national audit system reform.

\section{Annotation for the Optimizing Direction of National Audit System}

\subsection{The Possibility of Fundamental National Audit System Reform in the Short Term}

There are many viewpoints about national audit reform, such as "Legislation Theory" [12], "Upgrading Theory" [13], "Two-track System Theory" [14], "Merge Theory" [15], "Democratic Negotiation Theory" [16], and so on. The above viewpoints are based on the analysis of the problems existing in the current national audit system and put forward the reform paths which represent the directions of national audit system 
reform in the future, but they don't necessarily suit for the current situation of political, economic and social development. Under the existing political system, the public lacks the ability to influence institutional reform, and local interest groups can't actively promote institutional change because of vested interests. Therefore, the induced institutional change of the national audit system can't take place in a short time. The leading force to promote the mandatory institutional change comes from the central government, however, does the central government have enough power to promote the reform of the national audit system? At present China's political system reform isn't so completed, the profound effect of historical traditions is difficult to eliminate in the short term. In a long period of time, the current auditing system still has improvement spaces in efficiency. Chinese government's auditing system reform is a systematic project, now it is not the right time. One of the principles of audit system reform should be "reform should have realistic possibility" which is refined into ten elements, proposed by Yang Suchang and Xiao Zezhong (2010). The "realistic possibility" is just the "political rationality" proposed in this paper. Only when the "political control capability coefficient" $R_{2}$ is in the interval $\left(Q_{1} R_{1} / Q_{2}, 1-\right.$ $Q_{1}\left(1-R_{1}\right) / Q_{2}$ ) in national audit system reform, will it be possible to promote the reform of the audit system. Without major changes in the political system and historical tradition, the government audit system won't undergo significant changes (Shuguang Ma, 2006). It is disadvantageous to carry forward the national audit system reform too early surpassing the constraints of political system and historical tradition: on the one hand, it's adverse to the balance of different stakeholders (especially when the influences of local interest groups are not balanced), one the other hand, it's not conducive to carry out auditing, therefore, it hinders the development of national audit.

\subsection{The Interaction Between Institutional Environment and Audit Effectiveness}

Path dependence Theory indicates that technological evolution or institutional change in human society is analogous to the inertia in physics, "choices made in past may determine the choices in the future" (North, 1990). Although the emergence, operation and development direction of the national audit system fundamentally depend on the development of social productive forces, national audit system is in the framework of national political system, it can't change without politics, economics, history and culture. Therefore, it has strong path dependence. The natural selection of "social Darwinism" (Peter Dickens, 2005) also indicated that, the cultural tradition, which had gone through the selection of preservation and abolition, had strong functional fixation and inertia effect in path dependence for the formation of the political system including the national audit system [17]. North (1991) believed that institutional environment was the most basic institutional rule of a society and the basic system for determining other social institutional arrangements.
As an endogenous "immune system" with prevention, disclosure and defense functions in the large system of national governance, national audit is an integral part of the national political system. The performance of national audit also depends on the state of good governance. The interaction between national audit and external environment is also identified by the academic circle. Jiaxin Wang et al. (2015) believed that the law, efficiency, transparency, responsibility, and integrity were the core elements of state governance. National audit played an important role in these core elements and was the foundation of state governance [18]. Lihong Chen et al. (2016) found through empirical research that strengthening the accountability of national auditing helped to improve the effect of Anti-corruption [19]. Dasheng Dong (2018) believed that national audit belonged to the administrative organizations in the framework of national governance and was the executive organ of economic supervision [20]. Baohou Sun (2018) believed that national audit played an important role in maintaining the national financial and economic order, improving the efficiency of financial funds, promoting incorruptness, and ensuring the healthy development of economy and society [21]. Since the 18th national congress of the communist party of China (CPC), the central government has kept on crackdowns on anti-corruption and strictly restricted consumption by public funds, providing a better institutional environment for the development of national audit, and the public also has higher expectations on the effectiveness of national audit. Therefore, although the economic development (productivity) phase determines the production, operation and development of the national audit system reform direction, political environment background and cultural traditions often determines the type of the national audit system and the specific content of the national audit, the choice of any national audit system is restricted by the system environment at a specific stage. The ideal state for the national audit system reform is to follow the path of "pareto Optimality". As an important part of the political system, the national audit system reform must be under the general environment of the political system reform. The "political rationality" of the political state determines that the national audit system reform is not allowed to challenge the existing political system. When the national audit system reform is not realistic in the short time, "path dependence" may become the inertia resistance of the state audit system reform, but on the other hand, it also provides the possibility to seek optimization path under the inherent institutional framework. It is the suboptimal way to optimize the audit system within the framework of the existing national political system.

\section{Conclusion}

Although "the objectives, modes, means and methods of the governance for different countries are different in different historical periods, achieving good governance is common pursuit" [22]. As an important link in the national governance system, the role of the state audit is mainly embodied in 
safeguarding national security, supervising and restricting the operation of power, strengthening anti-corruption, promoting democracy and the rule of law, safeguarding the rights and interests of people's livelihood, and deepening reforms. Regardless of whether there is a difference between the national governance model and the national auditing system or not, the basic functional orientation of the national audit is consistent, i.e., the national audit is an important and effective way for the state governance to achieve a good governance state, which itself is also promoting the external environment tends to good governance. Meanwhile, the development of state audit is inseparable from the influence and promotion of the external environment such as political system, social system, economic system, cultural background and productivity level. The good governance of state governance is conducive to the realization of the legitimacy, transparency and effectiveness of the state in the security system, power operation and control mechanisms, legal rules and social order, the protection mechanism of people's livelihood rights, economic development mechanism, etc. Therefore, the good governance of state governance and the good performance of state auditing are embodied in an interactive state (Figure 3). Under the state of good governance of state governance, the effectiveness of national auditing is improved, and the interaction between good governance of state governance and the effectiveness of national auditing is realized. It will be the optimization direction of the current national audit system.

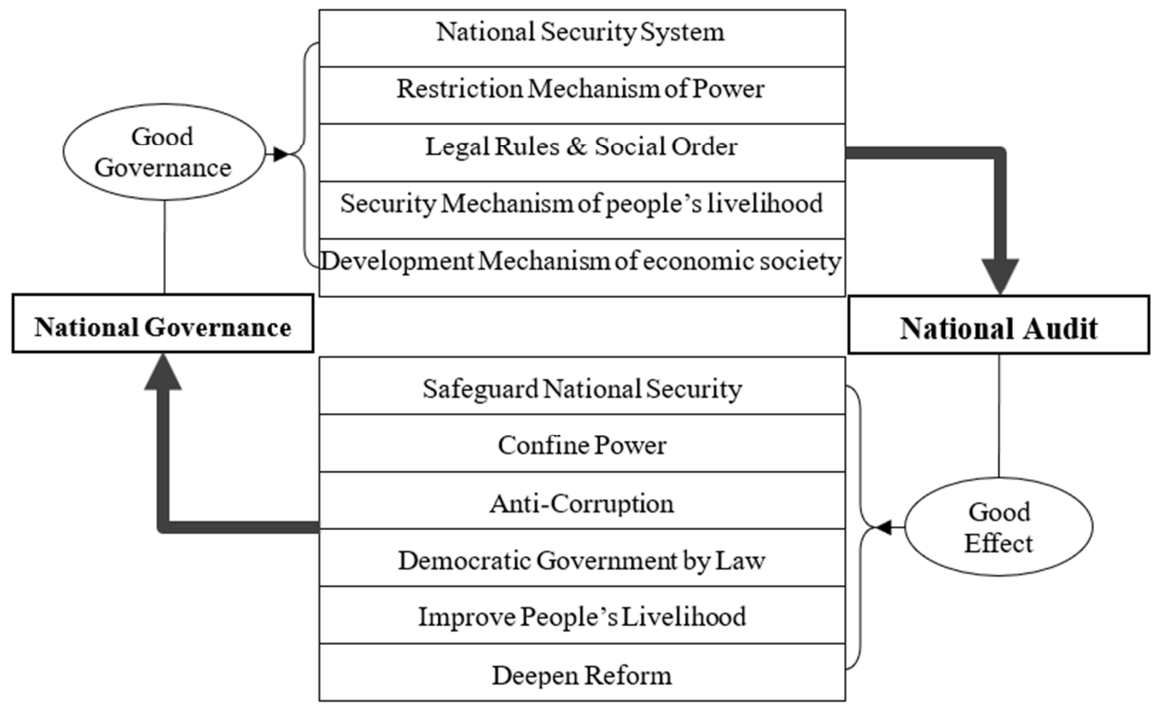

Figure 3. The Interaction of "Good Governance" and "Good Effect".

\section{Acknowledgements}

The Project Supported by Natural Science Foundation of Jiangxi in China (Grant No. 2018BAA208033) and Humanities and Social Science Foundation of Jiangxi in China (Grant No. GL18113).

\section{References}

[1] North, D. C, (1973). The rise of the western world: A new economic history, Cambridge University Press.

[2] North, D. C, (1990). Institutions, institutional change and economic performance, Cambridge University Press.

[3] Noth, (1991). Structure and changes in economic history, Sanlian Bookstore Shanghai Branch.

[4] Wei Zhang, (2010). The change of public opinion system: the possibility and limitation of empiricism transformation, The 10th China Institutional Economics Annual Meeting.

[5] Xiaoping Deng, (1994). Selected Works of Deng Xiaoping (Volume II), People's Publishing House.
[6] Jiayi Liu, (2012). On State Governance and State Auditing, Chinese Social Sciences No. 6, pp: 60-72, 206.

[7] Stevens, (1999). Collective Choice Economics, Shanghai People's Publishing House.

[8] Dianhua Zhu, (2019). The Audit Management System Reform under the Background of the Establishment of the Central Audit Committee: Logic and Method [J]. Hubei University of Economics, Volume17, No. 2, pp: 93-99.

[9] North, (1995). Outline of the Theory of Institutional Change, Reform, No. 3, pp: 94-98.

[10] Huai Li, Wei Deng, (2013). Subject theory innovation of institutional change and its related reaction research, Economist, No. 9, pp: 34-42.

[11] Junwei Lu, Hong Yin, (2012). The Dynamic Mechanism and Analysis Model of Government Accounting Reform — Based on the Theoretical Perspective of Institutional Change. Accounting Research, No. 2, pp: 57-64.

[12] Rongsheng Qin, (2004). Public Responsibility Economic Responsibility Theory and China's Government Audit Reform, Audit Research, No. 6, pp: 16-20.

[13] Ping Yin, (2001). The trade-offs and reforms of the current national audit system, Audit research, No. 4, pp: 43-46, 52. 
[14] Suchang Yang, Zezhong Xiao, (2004). On the reform of China's national audit "dual track system", Audit and economic research, No. 1, pp: 5-9.

[15] Shuguang Ma, (2006). Political System, Historical Tradition and Chinese Government Audit System Selection [J]. Auditing and Economic Research, No. 6, pp: 9-13.

[16] Taijun Jin, (2018). Consulting Democracy: Cognition and Construction in the Reform of National Audit System [J] Learning and Exploration, No. 10, pp: 66-71+191-192.

[17] Peter Dickens, (2005). Social Darwinism, Jilin People's Publishing House.

[18] Jiaxin Wang, Shiqiao Zheng, Ping Yin, (2015). National Auditing is the Foundation and Important Guarantee of State Governance: Theoretical Framework and Practice Analysis [J]. Audit Research, No. 06, pp: 3-8.
[19] Lihong Chen, Longping Zhang, Haiyan Zhu, (2016). Can national audit play an anti-corruption role? [J]. Audit Research, No. 03, pp: 48-55.

[20] Dasheng Dong, (2018). State, State Governance and State Audit: An Analysis Based on Marxist State View and China's National Conditions [J]. Audit Research, No. 05, pp: 3-11.

[21] Baohou Sun, (2018). Reflections on Several Issues Concerning the Audit of Socialist Countries with Chinese Characteristics in the New Era [J]. audit research, No. 04, pp: 3-6.

[22] Jiayi Liu, (2012). On State Governance and State Audit [J]. China Social Sciences, No. 06, pp: 60-72+206. 